Journal of Teaching and Learning with Technology, Vol. 7, No. 1, Spring 2018, pp. 59-69.

doi:10.14434/jotlt.v7n1.23368

\title{
An Educational Paradigm in the Midst of Shifting: Students' and Professors' Attitudes toward Classroom Technology
}

\author{
Emalinda L. McSpadden \\ Bronx Community College \\ City University of New York
}

\begin{abstract}
Many community college educators struggle with the notion of technology as integral to classroom learning, concerned about changing the very nature of what classroom learning means. For students, there are similar concerns regarding classroom experience, especially if students come from different educational backgrounds, generations, or levels of technological expertise. This qualitative research study compares student and professor experiences of classroom-specific technology use, and findings indicate convergent and divergent themes among students and professors specific to their classroom technology experiences. Students and professors agree that technology should be used in classrooms, despite sometimes hindering creativity and becoming a distraction. Students and professors disagreed in their satisfaction with amounts of classroom technology use and assurance in the efficacy of that technology use. These findings provide valuable insights and fundamental guiding principles for assessing goodness-of-fit between users and classroom technology.
\end{abstract}

Keywords: classroom technology, learning, attitudes

Over the last three decades, the social sciences classroom in the American higher educational landscape has seen the role of computers and technology use greatly expanded, with consistently increasing integration of technology into pedagogical strategies. This has made it crucial that the use of such technology be carefully assessed, ensuring efficacy of classroom implementation (Furr, Ragsdale, \& Horton, 2005). In order to understand the nature of technology use in college classrooms and potential successes, the focus of research has often considered student and professor attitudes toward technology use. For example, it has been found that successful adoption of a classroom technology depends heavily on student comfort level with use of the technological tools; with more exposure to computer technology in the classroom, students develop increased comfort and express a preference for using technology in future learning (Spinelli, 2001). It has also been found that student comfort with classroom technology use strongly impacts the development of student proficiency in skills and attitudes that are valued in the workforce beyond college (Efaw, Hampton, \& Martinez, 2004; Mackinnon \& Vibert, 2002). Finally, evidence suggests that the use of technology in the classroom has positive effects on both intellectual growth and classroom experience among students (Nelson \& Kuh, 2005). Multimedia use has been shown to enable student engagement in their learning, increasing general comprehension of conceptual material, and resulting in an increase in motivation to learn (Mayer, 2005). When considering professors’ perspectives regarding classroom use of technology, research often focuses on obstacles to technology adoption. Some factors identified as preventative to adoption of new technologies by faculty include a fear of change, reluctance due to the need for additional time commitment, worries that they might appear incompetent, 
fear of failure at attempted use, and a lack of time to modify or customize teaching strategies to include new technologies (Rutherford \& Grana, 1995; Peluchette \& Rust, 2005; Jacobsen, 1998).

Considering extant research, the current project is born of both the inspirations and the struggles that come of the academic context evident in the highly diverse students and faculty in community college settings. Diversity is often a relevant factor in community college classrooms, both in terms of a school's demographic composition (ages, ethnicities, educational backgrounds, cultural practices and beliefs, etc.) and its function as an academic institution (transitioning to a 4-year school, terminal degrees, remediation, a la carte course needs toward various certifications). In light of so many vital individual differences being a part of the classroom experience at community colleges, it becomes crucial for professors to understand these differences as a complementary context for both individual teaching pedagogies and, in this case, academic research.

The current project highlights the relationship many students and professors have with technology in social science classroom settings, including to what degree they find technology a help or hindrance to classroom-based learning. While various test outcomes exist in the current research literature that present correlational evidence for relationships between improvement in academic performance and classroom technology use (Efaw, Hampton, \& Martinez, 2004; Mackinnon \& Vibert, 2002; Nelson \& Kuh, 2005), the most effective strategies are yet to be clearly identified or fully understood. In addition, little research has been conducted to determine how different types of students (digital natives, for example, versus less technologically familiar students) actually feel about the use of technologies related to the classroom experience, their willingness to adopt changes, their technology expectations from their courses, and how technology contributes to their overall understanding of their own higher education experiences.

Also, while much focus is understandably placed by researchers on student performance outcomes, and therefore on student technology use and exposure, the experiences of instructors and how these issues apply to them are equally relevant for researchers to consider. Many faculty members find themselves willingly undertaking use of new technologies in the classroom, yet are not entirely confident in the efficacy of their endeavors as compared to more traditional teaching methods during lecture. Additionally, while instructors are aware of the various emerging trends leaning toward enhancing the classroom experience with technological supports, they are themselves not fully trained to use such methods to their greatest potential. It's important to remember that the gap between a one's desire and one's ability to integrate technology into classrooms teaching is not due to lack of access to technological tools in the classroom, but to a perceived incompatibility between the fundamental goals of classroom education and the nature of interactions between professors, students and resources (Voogt \& Pelgrum, 2005; Levin \& Wadmany, 2008). Furthermore, an overwhelming number of current instructors within higher educational settings were not taught with these methods when they themselves were students of the higher educational system. They might therefore lack a fundamental understanding of not only how it feels to be in a technologically-rich classroom setting as a student, but also how such an experience is actually perceived by today's students, many whom are digital natives with a differently inherent lived understanding of technology use than most of their professors $(\mathrm{Gu}$, Zhu, \& Guo, 2013).

Accounting for such juxtapositions present within the classroom dynamic, not only between educators and students but also between classroom technologies and user/consumer stakeholders, academic institutions have attempted to ensure that ample training opportunities are available to support both professors and students. At the institutional level, workshops designed 
for students typically address campus-wide internet functionality, academic registration and payment interfaces, or email and Blackboard navigability, none of which necessarily serve to address either classroom technologies or course-specific needs related to technology use. Institutional supports available to professors are somewhat more specific, as they are typically inclusive of the same components as the training available to students but also cover issues relating to SMART board use, Microsoft PowerPoint, Prezi, and more detailed explanations of Blackboard file sharing and module construction. When all such efforts are in place, professors are still left to make the final decisions of which technologies are relevant to the needs of a given course, topic, and constellation of students in a particular classroom (Guzman \& Nussbaum, 2009). Very little is known or provided to inform these decisions, resulting in a trial-and-error process with only occasional feedback loops in place to inform future modifications. Such feedback loops are either put in place by the professor as a systematic appraisal process, or are discovered serendipitously when, too late in the semester for which to make adjustments, the grades of students in a class give indication that something isn't working as expected or hoped.

\section{General Use of Classroom Technology}

Attitudes held by college students toward classroom technology draw from their preference of technology use for academic purposes outside of the classroom. Student ratings of devices they feel are most important to academic success can shed light on their preferences; Dahlstrom (2012) found that, in a sample of 10,000 undergraduate respondents, 85\% felt laptops to be academically necessary, $45 \%$ believed tablets were crucial, $37 \%$ endorsed smartphones as a requirement for academic work, and 31\% stated needing e-book readers. Students overwhelmingly report wanting the ability to access academic resources on their mobile devices; $67 \%$ of students' smartphones and tablets are reportedly being used for academic purposes, a rate that nearly doubles each year (Dahlstrom, 2012). Generally, professors in community college settings are encouraged to employ technology by their respective administrations, given the supports in research for its use. Basic classroom technology use among college professors include the use of PowerPoint slides, short videos, incorporating the use of websites in class, utilizing technologically enhanced "smart boards," and integrating course materials with Blackboard or other such web-based academic interface platforms. More recent classroom adoptions include Pinterest, YouTube, Podcasts, blogs, cellphones, mobile apps, social media outlets such as Facebook and Twitter, and various publisher-provided proprietary applications designed to pair with course textbooks.

\section{Technology in the Classroom: Areas of Concern for Learning}

For those professors harboring concerns about using technology in their classroom teaching, it can be argued that there are legitimate reasons for worry. Attention span among college undergraduates, for instance, should be considered when designing a lecture or curriculum that includes potentially distracting technology. In a conventional classroom lecture setting, the first attention lapses (lasting 1 minute or less) occur 30 seconds into a 30 to 50-minute lecture; lapses occur more frequently as the lecture progresses, and about every two minutes by the end of the lecture (Bunce, Flens, \& Neiles, 2010). While well-used technology could serve to improve attention, it might also result in further hindering the already difficult task of focusing attention on lecture material and its delivery.

Efficacy of classroom methods: Students with lower GPAs tend to use their small mobile devices for academic purposes more frequently than those with higher GPAs. The same is true with the relationship between GPA and academic use of e-book readers (Chen \& 
Denoyelles, 2013); a recent study analyzing blended learning classrooms found only $50 \%$ of students watched lecture videos on a regular basis, and $40 \%$ watched several weeks of videos in one sitting (Gosper et al., 2008).

The Current Project and the Classroom Generational Gap

This project aims to understand the interpersonal classroom dynamic as it is experienced by various students and instructors at Bronx Community College, given that so many students are, in terms of technology, "digital natives," while so many professors are more akin to being “digital immigrants” by comparison. According to Prensky (2001), “today's students are no longer the people our educational system was designed to teach." A fundamental assumption therefore must be grappled with by today's educators: traditional classrooms are the realm of the digital immigrant professor's educational history; the experience of being a student in a technologically advanced classroom is novel and foreign. By exploring the nature of this incredibly nuanced phenomenon, it is hoped that improvements can be made possible on several fronts.

First, an inquiry focusing on classroom technology use provides a point of feedback regarding how students understand the technologies being used as helpful, hindering, or nonimpactful, providing this information as an additional supplement to the data available to professors when grading exams or other work demonstrative of comprehension. This can also allow for professors to reflectively assess and adjust their current practices to attune them more appropriately to student experience, thereby enhancing the efficacy of lectures and activities. Finally, administrators can gain valuable insights into the experiences of students and instructors, thereby allowing for the creation and design of technological training supports better suited to the overall needs of those they hope to help.

The purpose of this project was to focus on and compare the classroom experiences of students and teachers regarding their use of technology as learning or teaching enhancement. College educators who are more at ease with traditional lecture methods may find themselves conceptually struggling with adopting the notion of technology as integral to the classroom learning process, since it may result in changing the very nature of their views on classroom learning, particularly in terms of meaningfulness and qualitative efficacy. This point of view is often in direct contrast with what research indicates is more akin to student attitudes toward technology use in the classroom. Here, then, can be found a strong argument for qualitative research: such exploration allows for in-depth consideration of student and teacher experience, as well as providing valuable insights into how primary stakeholders within the classroom experience. A qualitative inquiry allows for a conceptual understanding of stakeholder relationships with technology, both as a classroom learning tool and as a means of interaction with and assessment of one another.

\section{Method}

\section{Participants}

Nine professors (6 females and 3 males, teaching courses in psychology, sociology, and human services) and 24 students (Freshmen and Sophomores, 14 females and 10 males) in the Social Sciences department of Bronx Community College participated in the study. All were either teaching or enrolled in classes that regularly utilized technology in the classroom (including PowerPoint, Prezi, internet access, YouTube videos, computers, tablets, etc) as well as beyond 
the classroom (homework and study both expressly reliant at least in some part on technology). Given the diversity of the student population comprising the enrollment in our courses, and in light of the numerous sections and professors of various employment levels teaching, the department provided a good illustration of both the diversity issues present in many courses at the college and the typical variations in technology use. The subjects were recruited from multiple course sections, all of which use technology to enhance classroom-specific time and interaction at least $50 \%$ of classroom time.

\section{Procedure}

Data was collected for this project via open-ended interviews with each participant, which were audio recorded and transcribed for the purposes of analysis. By asking open-ended questions that prompt responses from participants regarding their individual experiences with classroombased technology, it becomes possible to extract from that data individual nuance in experience, which can then be compared to those of other participants' responses. The nature of these questions is such that they remain broad enough for various individual interpretations, while still retaining focus upon the topic of classroom technology use. The interview consisted of the following questions:

1. Describe, in general, all technology use for your class, including both your professor's/students' use of technology and your own use.

2. Think about an example of a time when you were in that class and you found the use of technology was particularly HELPFUL or conducive to the classroom experience. Describe in as much detail as possible.

3. Think about an example of a time when you were in that class and you found the use of technology was particularly UNHELPFUL, inconvenient, or detrimental to the classroom experience.

4. Do you consider yourself to be technologically savvy? Do you consider your professor/students to be technologically savvy? Describe experiences that have helped shape your view.

5. Do you think that more/less should be done with technology in order to enhance your classroom experience?

6. In your opinion, how does the experience of being in this class differ from a class that doesn't use technology as much?

7. Have you ever felt overly-dependent on technology during a lecture, or that there was any kind of interaction that couldn’t happen as well or at all without the technology you use?

\section{Data analysis.}

A qualitative existential phenomenological data analysis was used to identify convergent and divergent (between stakeholder groups rather than within-groups) themes within the responses; the analysis involved the isolation of critical incidence exemplars within the data, outlining areas of importance/concern among the interviewed stakeholders (Garza, 2004; Wertz et al, 2011). The method employed for this research involves the use of sections within the data which hold 
thematic value. During this process, the researcher identifies "thematic moments" in each of the participant's data; "the moments identified by the researcher present an aspect or face of the phenomenon under investigation -a sort of touchstone moment by which the rest of the data can be rendered sensible from a particular vantage point” (Garza, 2004, p. 133). The element to be focused upon most specifically in terms of themes in the existential-phenomenological material includes the interface with classroom technology as experienced by each participant; the analysis then elucidates major themes evident in each participant's experience, and then how those may or may not converge or diverge with the experiences of others taking part in the study.

\section{Results}

The following are the four convergent themes that resulted from the analysis described above, followed by the three divergent themes also discovered in the data. Convergent themes were those which were evident in data from either all or nearly all participants in both the student group and the professor group. Divergent themes were themes that were commonly endorsed by members of one group in one way while being contrasted by respondents in the other group. In addition to descriptions of each theme, exemplar statements from participants in each group are also included to further describe the themes in their own words.

\section{Convergent Themes}

There were four main convergent themes found in the fully compiled data from both student and professor groups: 1) technology as a distraction, 2) expectation of participant ability, 3) overwhelming endorsement for overall use of technology, and 4) technology as a hindrance to creative possibilities. In both participant groups, all four of these themes were clearly and overwhelmingly endorsed by all or nearly all participants.

Convergent Theme \#1: Technology as a distraction. Among all students and professors in the study, statements were made describing the use of technology in the classroom as notably distracting from the project of learning or lecturing. In particular, the use of cellphones and laptops were most commonly mentioned by members of both groups, but PowerPoint slides were also considered distracting to the flow of the lecture by both students and professors.

Student \#2: "When my boyfriend texts me, I tell him I'm in class, but I still pull out my phone and deal with that text, so I've lost that part of the lecture. I don't know why; I can't stop checking my phone!"

Professor \#4: "I let my students keep their phones on during class, because it's not realistic for a lot of them to put them away, and they really do use them for class; I pay for that by losing them during lectures, pretty much constantly."

Convergent Theme \#2: Expectation of participant ability. All but one student and all the participating professors reported perceiving the members of the other group as being highly adept at technology use of certain types. Students and Professors agreed that students were highly capable cellphone users, while students perceived professors as being more skilled at using desktop computers than students in general. (The student that did not feel this way was herself a computer science major.) 


\section{McSpadden}

Student \#5: "My professor knows what she's doing. In a lot of ways, more than me, and I'm pretty good. I'm better with my phone than with a computer, but I'm good; I think she's better."

Professor \#6: "I think overall my students think of themselves as tech savvy... thing is, they don't always use it in the way we want them to use it. Can they? Yes. They're comfortable, they're used to it. Better than me in many ways, for sure."

Convergent Theme \#3: Overwhelming endorsement for overall use of technology. All students and professors found that technology was more help than hindrance to the project of classroom learning. Although respondents were asked to focus on one course when considering their answers during the interview, this question led the majority of respondents in both group to answer more generally about their views regarding technology use in classroom settings.

Student \#19: "I feel like technology really helps overall, for sure. The only time I don't think technology is helpful is when it isn't working, like if my professor can't get something to work or I can't get a signal in our classroom."

Professor \#3: "Showing a video, hearing other people besides me talking about things, empowering people to go online... I think it results in more participation, and it always seems more powerful."

Convergent Theme \#4: Technology as hindrance to creative possibilities. This theme arose without an explicit question to prompt it directly, emerging from both the question about technology being unhelpful and the question addressing feelings of over-dependence on technology. All but one professor and all but two students endorsed the attitude that technology use was experienced in the classroom as being prohibitive of exploring creative possibilities during the lecture, and for both professors and students.

Student \#7: "I get that it's more convenient for professors to use technology and not write on the board. They just click, click, click. Writing on the board changes it up sometimes, though. I pay attention differently when he does that. With technology, you know you can sort of doze off. Mixing it up can be good."

Professor \#8: "Using the board makes you think on your feet, as you're discussing things with students. They benefit a lot from PowerPoints, but there does seem to be something cumbersome about being locked into a slide presentation."

\section{Divergent themes}

These resulting divergent themes, unlike the convergent themes that precede them, were fundamentally disagreed upon by the two participant groups. Three major divergent themes emerged from the data: 1) certainty of the efficacy of technology as a learning aid, 2) satisfaction with amounts of technology use, and 3) a view of technology as necessary for a quality lecture experience.

Divergent Theme \#1: Certainty of the efficacy of technology as a learning aid. This and the other divergent themes found in the data demonstrate instances when groups disagreed on a topic on which there was overwhelming within-group consensus. In this case, students unanimously endorsed that the use of technology in classrooms aided in their learning, whereas 


\section{McSpadden}

all but one professor felt unsure that their use of technology in their classrooms was entirely effective in enhancing the lecture for the purposes of student learning. (The professor who felt confident in the technology efficacy of her classroom had recently completed a self-evaluation of her course where she identified areas of improvement specific to her introduction of classroom technologies during lecture.)

Student \#15: "It's so helpful to be able to Google something in the middle of class or look something up; sometimes I don't know how I would learn anything without being able to do that."

Professor \#1: "I often wonder just how effective it is in improving students learning and retention. Does technology actually improve their performance, or is it just bells and whistles that make the classroom more interesting?"

Divergent Theme \#2: Satisfaction with amounts of technology use. The interview protocol asked that respondents answer all questions specific to one particular course and instructor, and the course in question must utilize technology during lecture or classroom hours for at least $50 \%$ of that time. When keeping those courses in mind, students unanimously endorsed feeling that the amount of classroom technology was either adequate or exceptional, while all professors (all social science professors using technology at least 50\% of the time in their classrooms) unanimously felt they ought to be imbedding more technology use.

Student \#14: "I don't think we need any more technology; I think it's a great amount. It's good to have the PowerPoints and videos to refer to. It's not as boring. And if I zone out, it's easier to come back to what's going on. I can just look at the slide."

Professor \#2: "I would love it if there could be more. I could definitely do a better job, and they could do with having more opportunities for interaction through technology, maybe with each other. But I know there's a lot more I could be doing."

Divergent Theme \#3: View of technology as necessary for quality lecture experience. This theme illustrates yet another area in which students and teachers have different degrees of trust in the assumption that technology is always best to incorporate into classroom time; for students, it was unanimously agreed that technology is necessary in order for a classroom experience to qualify as what they would consider "high quality," while professors were less convinced of this premise. Unlike Divergent Theme \#1, this theme is more evocative of the overall experience of the lecture time rather than its role as an aid to learning efficacy.

Student \#7: " When there's no PowerPoint, it's really just boring. I just start falling asleep. It's just endless talking. Just give me something to look at. I think if we had computers in the class, even, it could all be even better."

Professor \#4: "As a teacher, it can sometimes just be a pain to get the technology you need, so sometimes I have to rely on myself with just a chalkboard. It makes me do things differently... I don't know if it benefited students, but it benefited me. Sometimes, (technology) can be too much of a crutch"

\section{Discussion}

This study compared the social sciences classroom experiences of students to those of professors regarding their use of technology during lecture and classroom time. By using a qualitative research approach, student and professor experiences were compared based on 
thematic content of interview responses, providing interesting results and insights. It is interesting, for instance, that both students and professors are in agreement that technology in the classroom often proves a distraction when in the context of a lecture, sometimes in spite of being intended to enhance the message of that lecture. Some students mentioned finding PowerPoint slides or Prezi presentations to be only somewhat helpful in terms of really listening in class, since they would often focus more on the visual stimulus than on what the professor was saying. Professors, on the other hand, were more often concerned with the distraction that non-class-specific use of technology created when taking place during class, although they also felt those same devices were often useful, even necessary, when used appropriately. It is also valuable to see the mutual expectation of the part of both students and professors that members of the other group are skilled in the use of technology, often expressing a perception of the other being more capable in specific technology use, and these assessments of capability being made based on classroom experience of one another's uses of technology. Finally, it is striking to note the agreement between students and their professors that, while technology use does often result in hindering creativity during lecture sessions (in terms of dictating the nature and pace of the discussion in such a way as to limit spontaneous deviation), there was still a universal and overwhelming endorsement for the use of technology among all respondents from both participant groups.

Also interesting are the areas where student attitudes differed from those of professors regarding their experiences of classroom technology use. While students maintained a certainty that technology was an aid to their learning process, professors remained skeptical. Instructors did regularly indicate that, with more evidence to bolster their hopes, they could feel more secure in the actual efficacy of their efforts with technology. Going to such lengths, however, as to verify that efficacy seemed, for some, overwhelming, and, for others, too time-consuming. Another point of difference was the general level of satisfaction with the amounts of technology used in these courses. Students ranged from content to highly satisfied or even impressed with their levels of exposure to technology in class; professors in the study demonstrated an insecurity that was similar in tone to that of the issue of efficacy, stating that there must surely be more they could be doing, and to greater effect. In addition, while students see technology use in their classes as a necessary component for any lecture that hopes to be deemed of high quality, professors are once again in a position of doubt, unable to comfortably speculate that technology is so constantly necessary for their classroom lecture time to be fruitful. Many professors, though arguably not necessarily digital immigrants, were likely taught by instructors who were undoubtedly far less technologically capable or well-versed (especially since so many current technologies were not necessarily yet in existence, at least in their current form, and therefore not as readily used in classrooms as recently as five to ten years ago). The concept of a technologically enhanced lecture as being the standard for highest quality could threaten to symbolically invalidate the many years of non-technologically enhanced lectures that formed much of their own academic experiences.

It is inevitable that new and emerging technologies will become more readily and consistently available to professors, allowing for curriculum and instruction in community colleges to become even more interactive. The integration of technology in classrooms, when used appropriately, has the potential to increase attention among students, underscoring why so many professors and administrators are advocating for an increase in technology use and awareness in curriculum planning (Avila, Biner, Bink, \& Dean, 1995). Although content knowledge still reigns as the most valuable tool for effective teaching, professors must also 
attempt to create classroom experiences which, when integrating technology, provide for their students a diversified and effective mode of interaction with the course material. If utilized with care and informed planning, classroom technologies can be used in curriculums within the social sciences to clarify concepts and engage students with additional perspectives (Lachs, 2002). When college classes can not only integrate technology in the classroom, but also in assignments beyond classroom time, it serves to provide better preparation toward career readiness, particularly among students in community college settings seeking employment at the two-year educational level. Using technology in the classroom provides students with an opportunity to apply necessary and useful skill sets, as well as to consider different modalities of expression and collaboration (Shank, 2005). With all of these possibilities and potential, professors require a means by which to evaluate the efficacy of their efforts and must have the reassurances of proven tools by which to assess and evaluate classroom use of technology. With such ability to engage with proofs of effective learning resulting from technology use, professors can more confidently embark on more deeply integrative and creative technology usage with students, providing an enhancement in content learning in which both students and professors can place their trust.

\section{References}

Avila, R. A., Biner, P. M., Bink, M. L., \& Dean, R. S. (1995). Course materials presentation using videobased technologies: An evaluative study of college student performance and attitudes. Psychology in the Schools, 32 (1), 38-45.

Bunce, D. M., Flens, E. A., \& Neiles, K. Y. (2010). How long can students pay attention in class? A study of student attention decline using clickers. Journal of Chemistry Education, 87 (12), 1438-1443.

Courts, B., \& Tucker, J. (2012). Using technology to create a dynamic classroom experience. Journal of College Teaching \& Learning, 9 (2), 121-128.

Dahlstrom, E. (2012). ECAR study of undergraduate students and Information technology (research report). EDUCASE Center for Applied Research, Louisville, CO.

Efaw, J., Hampton, S., \& Martinez, S. (2004). Teaching and learning with laptop computers in the classroom. Education Quarterly, 27 (3), 10-18.

Furr, P. F., Ragsdale, R., \& Horton, S. G. (2005). Technology’s nonneutrality: past lessons can help guide today's classrooms. Journal of Education and Information Technologies, 10, 277 287.

Garza, G. (2004). Thematic moment analysis: A didactic application of a procedure for phenomenological analysis of narrative data. The Humanistic Psychologist, 32 (2), 120-168.

Gu, X., Zhu, Y. \& Guo, X (2013). Meeting the "Digital Natives": Understanding the acceptance of technology in classrooms. Educational Technology \& Society, 16 (1), 392-402. 
Guzman, A., \& Nussbaum, M. (2009). Teaching competencies for technology integration in the classroom. Journal of Computer Assisted Learning, 25, 453-469.

Jacobsen, D. M. (1998). Adoption patterns of faculty who integrate computer technology for teaching and learning in higher education. In proceedings of the Ed-Media and Ed-Telecom 98: World Conference on Educational Multimedia and Hypermedia \& World Conference on Educational Telecommunications (2-9), Freiburg, Germany.

Lachs, V. (2002). Book review: Making multimedia in the classroom: A teachers' guide. Interactive Learning Environments, 10 (3), 293.

Levin, T., \& Wadmany, R. (2008). Teachers' views on factors affecting effective integration of information technology in the classroom: Developmental scenery. Journal of Technology and Teacher Education,16 (2), 233-263.

Mackinnon G. R., \& Vibert C. (2002). Judging the constructive impacts of communication education study: A business education study. Journal of Education and Information Technologies, 7, 127-135.

Mayer, R.E. (2005). The Cambridge handbook of multimedia learning. New York: Cambridge University Press.

Nelson, T.F.L., \& Kuh, G.D. (2005). Student experiences with information technology and their relationship to other aspects of student engagement. Research in Higher Education, 46, 211-233.

Peluchette, J.V., \& Rust, K.A. (2005). Technology use in the classroom: Preferences of management faculty members. Journal of Education for Business, 80 (4), 200-205.

Prensky, M. (2001). Digital natives, digital immigrants. On the Horizon, 9 (5),1-6.

Rutherford, L.H., \& Grana, S. H. (1995). Retrofitting academe: Adapting faculty attitudes and practices to technology. $T$ H E Journal (Technological Horizons in Education), 23 (2), 82-87.

Shank, P (2005). The value of multimedia in learning. San Jose, CA: Adobe Systems Incorporated.

Spinelli, M.A. (2001). The use of technology in teaching business statistics. Journal of Education for Business, 77, 41-44.

Voogt, J., \& Pelgrum, H. (2005). ICT and curriculum change. Human Technology, 1 (2), 157 175.

Wertz, F. J., Charmaz, K., McMullen, L., Josselson, R., Anderson, R., \& McSpadden, E. (2011). Five ways of doing qualitative analysis: Phenomenological psychology, grounded theory, discourse analysis, narrative research, and intuitive inquiry. New York: Guilford Press. 